\title{
Processos de magnetização em pseudo-válvulas de spin baseadas em filmes de CoCrPt
}

\section{Vinícius S. Vianna*, Fanny Béron, Marcos V. Puydinger}

\section{Resumo}

Estudou-se a inversão magnética de filmes finos de CoCrPt separados por diferentes expessuras de $\mathrm{Ti}$, assim como o efeito da magneto resistência de sistemas de pseudo-válvulas de spin. O trabalho analiza os dados obtidos nos experimentos magnetoestáticos e magneto-elétricos relacionando-os com as espessuras de $\mathrm{Ti}$ entre as camadas magnéticas.

\section{Palavras-chave:}

Magneto Resistência Gigante, Pseudo-Válvulas de Spin, Spintrônica.

\section{Introdução}

Multicamadas de filmes finos de CoCrPt intercaladas com camadas de $\mathrm{Ti}$ formam pseudoválvulas de spin, essas podem ser utilizadas em dispositivos magnéticos baseados no fenômeno da magnetorresistência gigante. A espessura da camada de titânio entre as camadas de CoCrPt é diretamente responsável pelo acoplamento das camadas magnéticas (CoCrPt).

O projeto visou determinar as curvas de magnetização e estudar o efeito da magnetorresistência de pseudo-válvulas de spin com diferentes espessuras de camada não magnética (Ti)(Fig. 1).

A partir de filmes finos de CoCrPt intercalados com $\mathrm{Ti}$, utilizou-se de um difratômetro de raios-X para determinação da estrutura atômica e molecular dos cristais.

As amostras foram estudadas por um magnetômetro a amostra vibrante (VSM) de forma a encontrar a curva de magnetização dos filmes para campos magnéticos externos perpendiculares e paralelos ao plano das amostras. Os efeitos magnetoelétricos foram analizados a partir de dados obtidos do equipamento Physical Properties Measurement System (PPMS).

\section{Resultados e Discussão}

Por se tratarem de amostras pequenas (geometria de face aproximadamente quadrada de lado 5 $\mathrm{nm}$ ), encontrou-se dificuldades na obtenção dos dados por difração de Raios X (Fig. 2).

O magnetômetro a amostra vibrante (VSM) vibra a amostra a determinada frequência conhecida, gerando, devido a magnetização da amostra, uma corrente alternada de mesma frequência nas bobinas captadoras, dessa forma, fora possível identificar a magnetização das amostras de diferentes espessuras de Ti para diferentes orientações e magnitudes de campos magnéticos aplicados.

O equipamento Physical Properties Measurement System (PPMS) mede a resistividade das amostras enquanto um campo magnético externo conhecido é aplicado sobre a amostra, sendo possível calcular o efeito da magneto resistência.
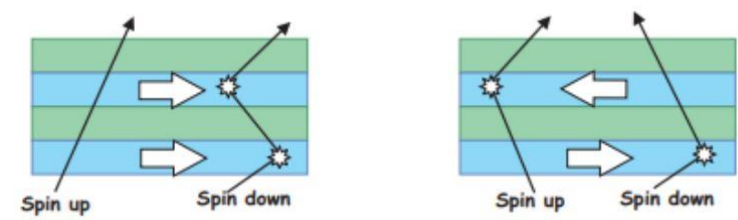

Figura 1. Funcionamento de uma pseudo-válvula de spin. As camadas em azul são as ferromagnéticas, em verde são camadas não ferromagnéticas.

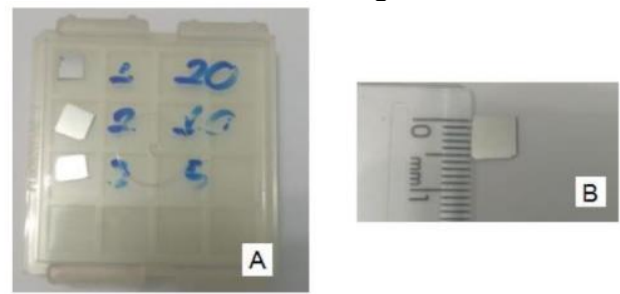

Figura 2. Amostras de pseudo-válvulas de spin produzidas na Universidade de Porto. A) Amostras de diferentes espessuras de $\mathrm{Ti}$ separadas para análise cristalográficas. Os números 5,10 e 20 representam as respectivas espessuras das camadas de $\mathrm{Ti}$ em nanômetros.

\section{Conclusões}

Experimentos visando encontrar as curvas características magnetoestáticas e magnetóelétricas das amostras, possibilitando inferir a respeito do acoplamento das camadas magnéticas a medida que a expessura da camada de Ti varia, serão realizados com o auxílio de equipamentos dispostos no laboratório.

Testes ocorreram sem impedimentos relacionados aos equipamentos, permitindo a prática do aprendido na literatura e abrindo possibilidades para novos testes. Os experimentos relacionados a difração de raios-X não tiveram bons resultados devido a pequena área superficial das amostras

\section{Agradecimentos}

Essa trabalho teve suporte do Conselho Nacional de Desenvolvimento Científico e Tecnológico - CNPq e da Fundação a Amparo à Pesquisa do Estado de São Paulo - FAPESP.

1S. Iwasaki andY. Nakamura, IEEE Trans. Magn. 14, 436 (1978).

2J. H. Judy, J. Magn. Magn. Mater. 287, 16 (2005).

${ }^{3}$ D. Navas, C. Nam, D. Velazquez, and C. A. Ross, Phys. Rev. B 81, 224439 (2010). 